\title{
Measuring Enjoyment of Ballroom Dancing in Filipino Americans Using the Physical Activity Enjoyment Scale
}

Asian / Pacific Island Nursing Journal April-June 2015: 1-9 (C) The Author(s) 2015 DOI: $10.1177 / 2373665815585320$ apn.sagepub.com \$SAGE

\author{
Alona D. Angosta ${ }^{1}$, Reimund Serafica ${ }^{1}$, and Sheniz Moonie ${ }^{1}$
}

\begin{abstract}
To advance knowledge about ways to promote physical activity in Filipino Americans, this feasibility study evaluated whether they enjoyed ballroom dancing and at the same time tested the validity of the Physical Activity Enjoyment Scale (PACES)for assessing enjoyment in this population. This study consisted of a single group of healthy Filipino Americans ( $N$ = 41) aged between 35 and 65 years residing in southern Nevada. Participants danced 45 min per week for 12 weeks and completed the PACES questionnaire to measure enjoyment at two time points (Week 4 and Week 12). Four participants dropped out during Weeks 2 to 5. Thirty-seven participants completed the 12 consecutive dance sessions. Descriptive statistics, paired- sample $t$ test, Pearson correlation, and a mixed-model ANCOVA were used for data analysis. Principal components analysis assessed the construct validity of the PACES. The mean age of the sample was 50.7 years. On average, the participants' PACES score significantly improved from Week 4 to Week 12. Age was negatively correlated with perceived enjoyment of dancing. In terms of the validity and reliability of the PACES, high construct validity and internal consistency of the PACES were noted. This study described the effectiveness of ballroom dance as a form of physical activity among first-generation Filipino Americans and confirmed the appropriateness of the PACES for assessing enjoyment in this population. Ballroom dance has the potential to promote physical activity and improve the cardiovascular outcomes of Filipino Americans and other populations who are at risk of heart disease.
\end{abstract}

\section{Keywords}

Asians, ballroom dance, enjoyment, exercise, Filipino Americans, physical activity, minority, PACES

Cardiovascular disease is the leading cause of death among Filipino Americans (Dalusung-Angosta, 2013; U.S. Census Bureau, 2010; Ursua et al., 2013). Although studies examining the prevalence of cardiovascular risk factors among Filipino Americans are scarce, published studies indicate that the risk factors are more common in Filipino Americans than other racial and ethnic populations (Ceria-Ulep et al., 2013; Ceria-Ulep, Serafica, \& Tse, 2011; Dalusung-Angosta, 2013; Dela Cruz \& Galang, 2008; Health Forum, 2003; Serafica, 2014). Filipino Americans are less likely to participate in regular physical activity than Native Hawaiians, Chinese, and Caucasians (Zou, Zhang, \& Maddock, 2012).

The American Heart Association (2015) indicated that regular physical activity is a way to reduce cardiovascular risk. A 30-min walk may reduce systolic blood pressure by approximately $4 \mathrm{~mm} \mathrm{Hg}$ (Park, Rink, \& Wallace, 2008). Another benefit of physical activity, especially when it is combined with a healthy lifestyle, is improvement in serum cholesterol and glucose levels (Pescatello, Murphy, \& Costanzo, 2000). In fact, aerobic activity for 35 min, 3 times per week for 4 weeks, decreases serum glucose, triglycerides, and low-density lipoprotein levels, and increases high-density lipoprotein levels (Derouich \& Boutayeb, 2002; Ghorban, Ziaee, Yazdi, Khoeyni, \& Khoshpanjeh, 2012). In spite of these known health benefits, many Filipino Americans remain physically inactive (Ceria-Ulep et al., 2013; Dalusung-Angosta, 2013; Health Forum, 2003; Zou et al., 2012). The most common reasons given for physical inactivity are lack of interest, dissatisfaction with the type of activity they are engaged in, and lack of time due to family and work obligations (Belza et al., 2004; Ceria-Ulep et al., 2013; Ceria-Ulep et al., 2011; Dalusung-Angosta, 2013; Dela Cruz \& Galang, 2008; Health Forum, 2003).

An activity that is enjoyable and sustainable is crucial in promoting an active lifestyle (Carraro, Young, \& Robazza, 2008). According to Mullen and colleagues (2011), enjoyment is a predictor of physical activity participation. Older

\footnotetext{
${ }^{1}$ University of Nevada, Las Vegas, USA

Corresponding Author:

Reimund Serafica, Assistant Professor, School of Nursing, University of Nevada, Las Vegas, 4505 Maryland Parkway, Box 453018, Las Vegas, NV 89154-3018, USA. Email: reimund.serafica@unlv.edu
} 
adults reported that enjoyment was a motivation to participate in physical activity (O'Driscoll, Kate Banting, Borkoles, Eime, \& Polman, 2014). To help prevent cardiovascular disease, the American College of Sports Medicine (ACSM) recommends 30 min per day, or 150 min per week, of moderately intense physical activity (ACSM, 2011). Moderately intense physical activity is defined as a $50 \%$ to $70 \%$ increase in maximum heart rate and includes dancing, vigorous walking, or jogging (ACSM, 2011; Centers for Disease Control and Prevention [CDC], 2012; U.S. Department of Health and Human Services, 2008). Among these activities, dancing has been shown to be the most attractive and exciting to many people, particularly in Asian populations (Vahabi, Beanlands, Sidani, \& Fredericks, 2012). Vahabi et al. (2012) indicated that dance is a pastime most people have engaged in at some point in their lives. Dance is an expression of a deep-seated biological drive for synchronized movement to a rhythmic stimulation (Alpert, 2010), which brings back good memories, allows one to establish cultural connections with others, and provides an opportunity for socializing (Silva Lima \& Vieira, 2007). Dance has been shown to be a culturally tailored physical activity intervention that can increase physical activity and improve cardiovascular health (Hovell et al., 2008). Furthermore, dance can maintain an individual's interest in the activity, creating the potential for sustainability (Alpert, 2010; Song, June, Kim, \& Jeon, 2004).

One type of dance that is gaining popularity is ballroom dance - a collective set of dances using a variety of music (Borges et al., 2012). Specific types of ballroom dance currently increasing in popularity are the cha-cha, salsa, and rumba. In salsa, the dancers move their weight through stepping, causing the hips, shoulders, and arms to move. While stepping and moving the hips, shoulders, and arms, the upper body level is maintained. In rumba, the dancers move their hips slowly. The slow hip movements are generated by bending and straightening the knees. Cha-cha is similar to rumba, but the movements are faster. The hip movements are caused by bending and straightening the knees. The feet and ankles move fast and the quick steps are maintained throughout the dance. These dances are considered to be moderately intense physical activities (ACSM, 2011; CDC, 2012; Lankford et al., 2014).

In addition to their health benefits, these dances can be practiced anywhere (e.g., at home, at a dance studio), anytime, with or without a partner, or be performed as a group. To date, there are no studies that have examined the psychological benefits of ballroom dance among Filipino Americans. It is unknown if ballroom dance is enjoyable and if it promotes physical activity in first-generation Filipino Americans.

This feasibility study sought to answer the following research questions:

Research Question 1: Is ballroom dance an enjoyable and a sustainable form of physical activity among firstgeneration Filipino Americans?
Research Question 2: Is the Physical Activity Enjoyment Scale (PACES) a valid tool for measuring enjoyment of physical activity in first-generation Filipino Americans?

\section{Conceptual Framework}

The social cognitive theory by Bandura (1986) guided this study. The social cognitive theory has been used in health intervention studies as the underlying behavior change agent including physical activity interventions (Fjeldsoe, Miller, \& Marshall, 2010; Riley et al., 2011). The goal of the social cognitive theory is to elucidate how people regulate their behavior through control and reinforcement to achieve goaldirected behavior that can be maintained over time (Bandura, 1986). According to Bandura, individuals act intentionally within a system of dynamic and reciprocal interaction of three factors: person, environment, and behavior. The major concepts in social cognitive theory are behavioral capability, expectations, observational learning, reinforcement, reciprocal determinism, and self-efficacy. According to Bandura, self-efficacy perceptions help to shape individuals' efforts, affective experiences, and enjoyment of physical activities, particularly at higher intensities. Consequently, enjoyment has a potential to increase self-efficacy and physical activity.

For the purposes of this study, the behavioral, personal, and environmental factors represent physical inactivity and barriers to physical activity. Physical inactivity is a common problem among Filipino Americans. Barriers to physical activity are lack of motivation, interest, and social support (Figure 1). The concepts in social cognitive theory in relation to this study include (a) ballroom dance intervention, which may potentially encourage individuals to engage in physical activity (behavioral capability); (b) benefits and types of ballroom dance, which may potentially increase enjoyment and physical activity (expectations); (c) participation in weekly dance activity at a dance studio, which may increase motivation and confidence to participate in regular physical activity (self-efficacy); (d) professional dance instructors may serve as role models and influence participants to engage in physical activity (observational learning); (e) weekly dance participation with other participants could potentially bolster enjoyment and motivation to engage in regular physical activity (reinforcement); and (f) group dancing at a studio every week and encouraging one another during dancing are dynamic avenues that could empower individuals to engage in physical activity (reciprocal determinism).

\section{Method}

\section{Design, Sample, and Setting}

This prospective study consisted of a single group of healthy Filipino American adults residing in Southern Nevada. A 


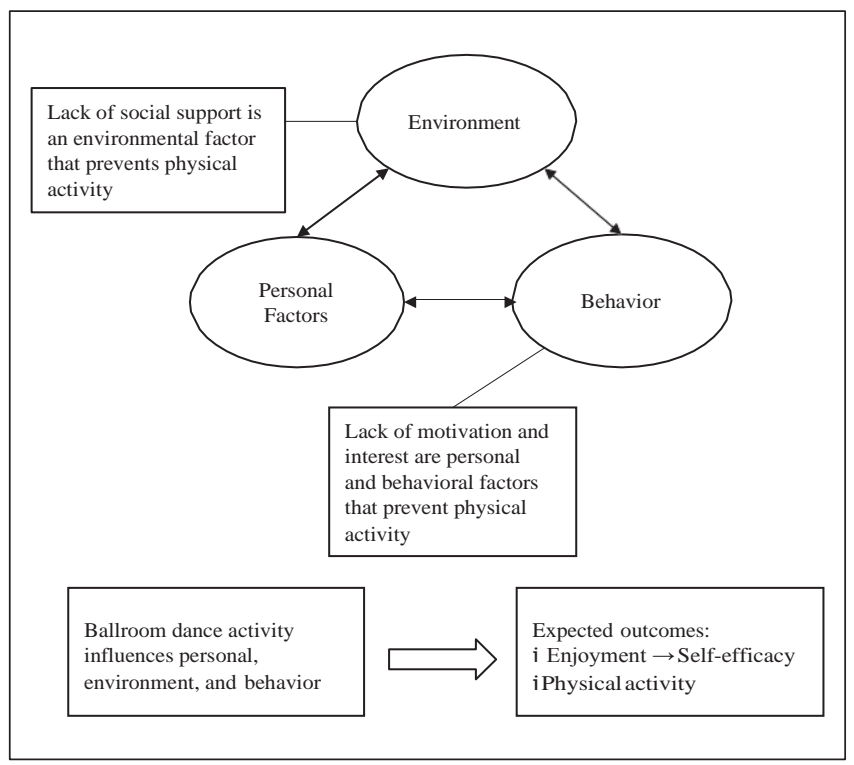

Figure 1. Conceptual framework based on social cognitive theory.

power analysis for a medium effect size determined that $N=$ 36 was necessary to achieve a power of $80 \%$ with an alpha of .05 (Cohen, 1988). Forty-one Filipino Americans were recruited and 37 completed the study (Figure 2). The dance sessions were held in a spacious ballroom dance studio in Southern Nevada, accessible to public transportation.

\section{Inclusion and Exclusion Criteria}

The inclusion criteria for this study were (a) Filipino Americans aged 35 to 65 years, (b) who can understand and read English, (c) who answered "no" to all questions on the Physical Readiness and Health Screening questionnaires, and (d) those without prior ballroom dance experience. Additional criteria included a mobile phone number and a valid email address for communication purposes and updates. The exclusion criteria were medical conditions that precluded participation in ballroom dancing, such as heart failure, advanced lung disease, paralysis, musculoskeletal/joint problems, or hearing/visual loss.

\section{Procedures}

The institutional review board of the University of Nevada, Las Vegas, approved this study. Participants were recruited by word of mouth, printed flyers, media (i.e., radio shows and newspapers), and by formal invitation during Filipino events. A member of the research team served as the main recruiter for this study. He is well known in the local Filipino community and is an active member of several local Filipino organizations. The 48 individuals who wanted to find out more about the study notified him by telephone or email. Of

\section{Recruitment}

48 individuals responded to printed flyers, newspapers, or called

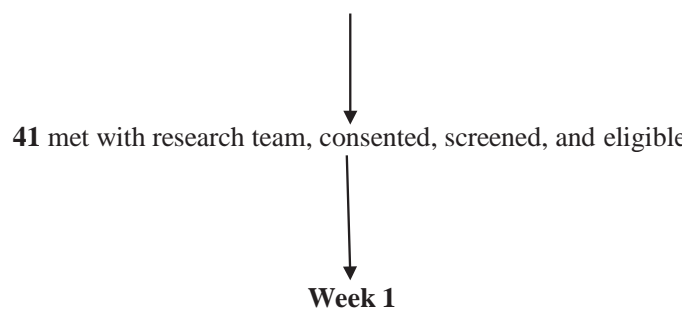

Orientation, introduction to dance steps

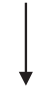

Weeks 2 through 12 Dance sessions (attendance recorded for each dance session)

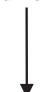
Completion of PACES
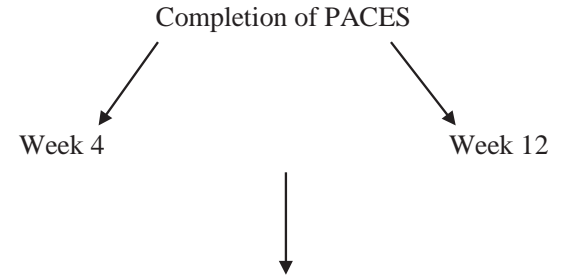

4 Dropouts during weeks 2-5

(1 illness, 1 family obligation, 2 work schedule conflict)

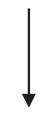

37 Participants completed the study

Figure 2. Participant flowchart and study timeline. Note. PACES = Physical Activity Enjoyment Scale.

them, only 41 showed up to meet with the principal investigator (PI) and research assistant for consent signing and for completion of the physical activity readiness and health screen questionnaires. The physical activity readiness questionnaire is a screening tool adapted from the ACSM to determine physical activity readiness of participants and to identify those at risk for a cardiovascular event during exercise (ACSM, 2011). The health screening questionnaire included questions regarding past medical history. The purpose of the health screening questionnaire was to identify individuals who had medical conditions that would exclude them from the study. Those who met the criteria were sent the dance schedule by email. Two days before each scheduled dance session, the research assistant telephoned participants to remind them of the class. In addition, every 2 weeks, the PI emailed the participants regarding their progress (i.e., follow-up activity status) and gave them study updates (i.e., dance schedule reminder, number of weeks into the dance program, type of dance lesson). Participants who missed two 
Table 1. Physical Activity Enjoyment Scale (PACES) Questionnaire.

\begin{tabular}{lllllllll} 
Please rate how you feel about the physical activity (ballroom dance) you have been doing \\
\hline *I enjoy it & 1 & 2 & 3 & 4 & 5 & 6 & 7 & I hate it \\
I feel bored & 1 & 2 & 3 & 4 & 5 & 6 & 7 & I feel interested \\
I dislike it & 1 & 2 & 3 & 4 & 5 & 6 & 7 & I like it \\
*I find it pleasurable & 1 & 2 & 3 & 4 & 5 & 6 & 7 & I don't find it pleasurable \\
* I am very absorbed & 1 & 2 & 3 & 4 & 5 & 6 & 7 & I am not all absorbed in this activity \\
It's not fun at all & 1 & 2 & 3 & 4 & 5 & 6 & 7 & It's a lot of fun \\
*I find it energizing & 1 & 2 & 3 & 4 & 5 & 6 & 7 & I find it tiring \\
It makes me depressed & 1 & 2 & 3 & 4 & 5 & 6 & 7 & It makes me happy \\
*It's very pleasant & 1 & 2 & 3 & 4 & 5 & 6 & 7 & It's very unpleasant \\
*I feel good physically while doing it & 1 & 2 & 3 & 4 & 5 & 6 & 7 & I feel bad physically while doing it \\
*It's very invigorating & 1 & 2 & 3 & 4 & 5 & 6 & 7 & It's not at all invigorating \\
I am very frustrated by it & 1 & 2 & 3 & 4 & 5 & 6 & 7 & I am not at all frustrated by it \\
*It's very gratifying & 1 & 2 & 3 & 4 & 5 & 6 & 7 & It's not at all gratifying \\
*It's very exhilarating & 1 & 2 & 3 & 4 & 5 & 6 & 7 & It's not at all exhilarating \\
It's not at all stimulating & 1 & 2 & 3 & 4 & 5 & 6 & 7 & It's very stimulating \\
*It gives me a strong sense of accomplishment & 1 & 2 & 3 & 4 & 5 & 6 & 7 & It doesn't give me a strong sense of \\
*It's very refreshing & 1 & 2 & 3 & 4 & 5 & 6 & 7 & It's not at all refreshing \\
I felt as though I would rather be doing something & 1 & 2 & 3 & 4 & 5 & 6 & 7 & I felt as though there is nothing else I would \\
else & & & & & &
\end{tabular}

Source. Adapted from Kendzierski and De Carlo (1991).

*Denotes reversal when scoring.

dance sessions were withdrawn from the study. During Weeks 2 to 5, 4 participants dropped out due to illness, family obligation, or scheduling conflicts. Altogether, 37 participants completed the study. As an incentive, participants received free ballroom dance lessons.

On consultation with an exercise physiologist and two professional ballroom dance instructors, the salsa, rumba, and cha-cha dance forms were selected. These dances were carefully chosen because of their popularity and level of intensity (Ainsworth et al., 1993; Haskell et al., 2007).

To accommodate the participants' varied schedules, dance sessions were held on either Friday or Saturday afternoon. Half of the sample joined the Friday session and half joined the Saturday session. Two nationally certified ballroom dance instructors, a female and a male, taught the dance classes. They used the same dance curriculum for both days to provide an equivalent intervention for each session. Because there were more females $(n=30)$ than males $(n=7)$ in the study, some participants brought their own dance partners. However, the partners were not part of the study. The dance instructors also provided their own students as partners. Although the student partners were not included in the study, they attended all dance sessions. The dance sessions were held once a week from September 28, 2012, to December 22, 2012. The dance sessions included the measurement of resting blood pressure, heart rate, weight, and weight circumferences; 10-min warm up and 10-min cool down; and 45 min of actual dancing. Thirtyseven participants completed the 12 consecutive dance sessions (Figure 2).

\section{Instrumentation and Analysis}

The PACES questionnaire was used to assess enjoyment of ballroom dance (Kendzierski \& De Carlo, 1991). It consists of 18 items scored on a 7-point bipolar rating scale. The participants were asked, "Please rate how you feel about the physical activity (i.e., ballroom dance) you have been doing" based on a scale of 1 through 7 . The PACES has items that are reversely scored (Table 1), with lower scores reflecting a greater level of enjoyment, for example, on Question 1, $1=I$ enjoy it to $7=I$ hate it. For questions without asterisks, higher scores indicate a greater level of enjoyment, for example, on Question 2, 1 = I feel bored to $7=$ I feel interested. The participants completed the PACES twice, at Week 4 and Week 12 of the study. The PACES questionnaire has been used in previous studies and provided evidence for validity and reliability. Motl and colleagues (2001) examined the factorial validity and construct validity of the PACES using exploratory and confirmatory factor analysis. They also tested the relationships among the measures in the PACES using the structural equation modeling. According to their study, the PACES demonstrated factorial validity and construct validity. Mullen and colleagues (2011) also examined the validity of the PACES using convergent and structural analysis. Findings from their study revealed that PACES was a valid measure. They also examined the reliability of the PACES calculated with standardized estimates using McDonald's omega coefficient. Results revealed good internal reliability coefficients for the PACES measure at Times 1 and $2(\omega \mathrm{s}=.93, .93$; Mullen et al., 2011). The PACES has not 
Table 2. Mean and Standard Deviation for Individual PACES Items and Scale Score $(n=37)$.

\begin{tabular}{|c|c|c|}
\hline & Preintervention & Postintervention \\
\hline Items & M score $(S D)$ & M score $(S D)$ \\
\hline *I enjoy it-I hate it & $6.54(1.04)$ & $6.84(0.60)$ \\
\hline I feel bored-I feel interested & $6.19(1.29)$ & $6.73(0.61)$ \\
\hline I dislike it-I like it & $6.49(0.90)$ & $6.78(0.63)$ \\
\hline *I find it pleasurable-I don't find it pleasurable & $6.19(1.47)$ & $6.81(0.70)$ \\
\hline *I am very absorbed in this activity-I am not all absorbed in this activity & $5.59(1.77)$ & $6.59(0.69)$ \\
\hline It's not fun at all-It's a lot of fun & $6.46(1.04)$ & $6.70(1.02)$ \\
\hline * find it energizing $-I$ find it tiring & $6.32(1.23)$ & $6.59(0.93)$ \\
\hline It makes me depressed-It makes me happy & $6.51(0.88)$ & $6.95(0.23)$ \\
\hline *It's very pleasant-It's very unpleasant & $6.46(1.12)$ & $6.92(0.28)$ \\
\hline *I feel good physically while doing it-I feel bad physically while doing it & $6.49(1.15)$ & $6.89(0.32)$ \\
\hline *It's very invigorating-It's not all invigorating & $6.30(1.13)$ & $6.89(0.32)$ \\
\hline I am very frustrated by it-I am not all frustrated by it & $6.27(1.12)$ & $6.51(0.87)$ \\
\hline *It's very gratifying-It's not at all gratifying & $6.49(0.99)$ & $6.59(1.17)$ \\
\hline *It's very exhilarating-It's not at all exhilarating & $5.92(1.66)$ & $6.68(0.78)$ \\
\hline It's not all stimulating-It's very stimulating & $5.92(1.77)$ & $6.76(0.69)$ \\
\hline $\begin{array}{l}\text { *It gives me a strong sense of accomplishment-It doesn't gives me a } \\
\text { strong sense of accomplishment }\end{array}$ & $6.32(1.18)$ & $6.57(1.17)$ \\
\hline *It's very refreshing-It's not at all refreshing & $6.41(1.14)$ & $6.78(0.67)$ \\
\hline $\begin{array}{l}\text { I felt as though I would rather be doing something else-I felt as } \\
\text { though, there is nothing else I would rather be doing }\end{array}$ & $5.73(1.54)$ & $6.14(1.29)$ \\
\hline PACES total scale score & $108.26(14.24)$ & $115.73(7.63)$ \\
\hline
\end{tabular}

Note. PACES = Physical Activity Enjoyment Scale.

*Denotes reversal scoring.

been used specifically with Filipino Americans, and reversing the value of the scores could create confusion. Therefore, PACES was piloted to three first-generation Filipino Americans who were residents of Southern Nevada. They indicated that the questions in the PACES were understandable and appropriate for this population. During the fourth week of the dance study, the questionnaire was administered to the participants. Prior to the completion of the questionnaire, the bilingual PI explained the directions carefully and thoroughly in both English and Tagalog (Philippine national language). The PI was also available for participants who needed minimal assistance in completing the questionnaire. Participants completed the PACES questionnaire again after the dance intervention (Week 12).

The paired-sample $t$ test was used to determine significant differences in the change of the mean score at Week 4 and Week 12. Descriptive statistics were used to characterize the age and gender of the study population and the overall PACES score as well as for the PACES individual items. Principal components analysis was used to assess the construct validity of the PACES.

\section{Results}

The mean age of the participants was 50.7 years $(S D=8.2$ years). There were more females $(n=30)$ than males $(n=7)$.
Descriptive statistics were acquired for the PACES score as well as individual items (see Table 2). On average, the overall mean of participant's PACES score improved from 108.26 $(S D=14.24)$ at Week 4 to $115.73(S D=7.63)$ postintervention (Week 12), a clinical and statistically significant improvement $(t=3.61, d f=36, p<.01)$. This suggests that ballroom dance was an enjoyable form of physical activity among the study participants. A significant and moderate bivariate correlation $(r=.47, p<.01)$ indicated that participants who had higher levels of enjoyment in physical activity at Week 4 of the dance intervention tended to score higher on their enjoyment of the physical activity at Week 12 of the dance intervention. Age was negatively correlated with perceived enjoyment of dancing at Week $4(r=-.388, p=.018)$, but not related to perceived enjoyment of dancing at Week 12 $(r=.164, p=.333)$. At Week 4, older participants enjoyed dancing less than younger participants; however, older participants enjoyed dancing as much as younger participants after completing the dance program. The interaction effect of age by time was significant when we ran the mixed-model $\operatorname{ANCOVA}(F=14.228, d f 1=1, d f 2=35, p=.001)$. This indicates that the dance intervention was more effective for older participants than the younger participants in terms of enjoyment.

The construct validity of the PACES was assessed using principal components analysis with data on Questions 1 
Asian/Pacific Island Nursing Journal, Vol. 1, Iss. 1 [2016], Art. 8

Table 3. Summary of Principal Components Analysis for PACES Measure $(n=$

\begin{tabular}{|c|c|c|}
\hline \multirow[b]{2}{*}{ Item } & \multicolumn{2}{|c|}{ Factor } \\
\hline & Preinterventio & Postinterventio \\
\hline *I enjoy it-I hate it & .89 & .85 \\
\hline I feel bored-I feel interested & .82 & .81 \\
\hline I dislike it-I like it & .86 & .93 \\
\hline *I find it pleasurable-I don't find it pleasurable & .73 & .84 \\
\hline *I am very absorbed-I am not all absorbed in this activity & .46 & .69 \\
\hline It's not fun at all-It's a lot of fun & .46 & .26 \\
\hline *I find it energizing-I find it tiring & .83 & .53 \\
\hline It makes me depressed-It makes me happy & .81 & .60 \\
\hline *It's very pleasant-It's very unpleasant & .87 & .52 \\
\hline *I feel good physically while doing it-I feel bad physically while doing it & .86 & .39 \\
\hline *It's very invigorating-It's not at all invigorating & .83 & .55 \\
\hline I am very frustrated by it-I am not at all frustrated by it & .41 & .80 \\
\hline *It's very gratifying-It's not at all gratifying & .92 & .53 \\
\hline *It's very exhilarating-It's not at all exhilarating & .54 & .79 \\
\hline It's not at all stimulating-It's very stimulating & .45 & .92 \\
\hline $\begin{array}{l}\text { *It gives me a strong sense of accomplishment-It doesn't give me a } \\
\text { strong sense of accomplishment }\end{array}$ & .89 & .60 \\
\hline *It's very refreshing-It's not at all refreshing & .93 & .94 \\
\hline $\begin{array}{l}\text { I felt as though I would rather be doing something else-I } \\
\text { felt as though there is nothing else I would rather be } \\
\text { doing }\end{array}$ & .68 & .59 \\
\hline Eigenvalues & 10.30 & 8.82 \\
\hline$\%$ of variance explained & $57 \%$ & $49 \%$ \\
\hline Cronbach's $\alpha$ & .91 & .84 \\
\hline
\end{tabular}

Note. PACES = Physical Activity Enjoyment Scale.

*Denotes reversal scoring.

through 18 at Week 4. The analysis yielded a single factor that accounted for $57 \%$ of the variance of the 18 items in the PACES. Factor loadings ranged from .41 to .93 (see Table 3). Internal consistency of the total scale was assessed with Cronbach's alpha, which produced a coefficient of .91 for the PACES' 18 items. The same procedure was performed with data at Week 12 on the same questions. Again, a similar principal components analysis yielded a single factor that accounted for $49 \%$ of the variance of the 18 items. Similar findings of high construct validity and internal consistency and reliability were obtained. Factor loadings ranged from .26 to .94 and overall Cronbach's alpha was .84 (see Table 3).

\section{Discussion}

This study revealed that ballroom dance was an enjoyable form of physical activity for first-generation Filipino Americans. Moreover, this study revealed that the PACES was valid and reliable, and an appropriate tool for the assessment of enjoyment of physical activity in this population. The literature indicates that enjoyment has important effects on an individual's quality of life and it should be viewed as a priority when the goal is to encourage healthy lifestyle habits (Carraro et al., 2008). Mullen and colleagues (2011) also viewed enjoyment as an important construct in terms of physical activity participation and maintenance. Enhancing intrinsic motivation through enjoyment could lead to an increased adherence to physical activity and promotion of the health benefits associated with it (Carraro et al., 2008). Despite the absence of studies on the benefits of ballroom dancing among first-generation Filipino Americans, findings from this study were consistent with those presented in the literature. This study suggests that enjoyment was experienced by the Filipino Americans in this sample. Participants were also satisfied with ballroom dancing as demonstrated by the improvement of their PACES scores between Week 4 and Week 12. Because ballroom dance is also considered a competitive sport (Butler, Mocarski, Emmons, \& Smallwood, 2014), this essence of noncompetitiveness among participants can be a factor in their success and may fit the noncompetitive exercisers in this study (Moreno Murcia et al., 2008; Mullen et al., 2011).

There are additional considerations specific to Filipino Americans that may have influenced their scores, including the overall effect of socialization with their kababayans (countrymen). New friendships and new social networks may have developed while the participants were enrolled in this study. These results agreed with prior studies regarding cultural factors and socialization as intrinsic motivators in 
sustaining a group exercise activity (Iso-Ahola \& St. Clair, 2012; Perez \& Cancela Carral, 2008). Peer influence and socialization can stimulate motivations and support a physical activity regimen. This was evident in the overall attrition rate of our study (only four participants dropped out) within the 12-week period. The positive effects of socialization while exercising produce not only psychological but also physiological benefits and are documented in the literature (Moreno Murcia et al., 2008; Thorton et al., 2005). For example, participants who dance together for leisure may not only increase their respective social networks but also encourage each other to be more active. Although the current study did not explore the clinical significance of these behavior changes, an increased satisfaction in this type of activity is likely to motivate others to engage in regular physical activity. This may also reduce the risks of various diseases, particularly the ones prevalent in Filipino Americans and can lead to improvements in their overall health. This study suggests that ballroom dance can be used in other Filipino American community-based venues to encourage physical activity as a health promotion alternative. Findings from this study support the following recommendations regarding community-based interventions intended to promote an increase in enjoyment during physical activity. Health care providers, health promoters, and nurses should consider different forms of physical activity to sustain motivation and enjoyment among first-generation Filipino Americans. Researchers working with Filipino Americans should modify the PACES by translating the questions in Tagalog and test its validity in measuring enjoyment among Filipino Americans in another generation.

\section{Limitations}

Results from this study should be interpreted cautiously. The sample was limited to first-generation Filipino Americans. Further assessment is needed to determine if physical activity enjoyment will vary among Filipino Americans in another generation. This study was specific to ballroom dance as a noncompetitive type of activity. It may not have adequately captured other intrinsic motivational factors, such as the desire to win in competitions, if the study was portrayed as competitive dance. Future studies, for example, could analyze and compare the effect of a competitive format against the results of this study. Another limitation was the number of females. There were more females than males in this study. Nevertheless, this study provides significant data for designing future intervention studies with the goal of improving enjoyment in physical activity and increasing motivation to exercise.

\section{Implications for Nursing}

This study has broad implications for one of the largest understudied ethnic minority population in the United States.
Nurse researchers and clinicians performing minority-oriented physical activity interventions should reinforce that ballroom dance is not just a social activity but also an activity that can be performed regularly. Ballroom dance is enjoyable; it has the potential to promote physical activity and it can be applied to clinical and community settings. Furthermore, ballroom dance has the potential to improve the cardiovascular outcomes of Filipino Americans and other populations who are at risk of coronary heart disease.

\section{Conclusion}

This study described the effectiveness of ballroom dance as a form of physical activity among first-generation Filipino Americans. This effectiveness was demonstrated by the enjoyment scores of the participants in a PACES survey and low attrition rate of the sample. The findings can be used to further explore ballroom dance and similar types of physical activity that will benefit Filipino Americans and other ethnic minority populations. Results from this study also confirmed the appropriateness of the PACES survey as an instrument for this population. Future researchers should be encouraged to pursue other forms of physical activity interventions to improve enjoyment and increase motivation to exercise among Filipino Americans and other multinational populations.

\section{Acknowledgments}

The authors would like to acknowledge the following individuals: Dr. Du Feng for statistical assistance, Dr. Fred Brooks for editorial assistance, and Dr. Rhigel Alforque-Tan and Mr. Victor Vapor for their assistance in recruitment and data collection.

\section{Declaration of Conflicting Interests}

The author(s) declared no potential conflicts of interest with respect to the research, authorship, and/or publication of this article.

\section{Funding}

The author(s) disclosed receipt of the following financial support for the research and/or authorship of this article: This project was supported by the grants from the National Center for Research Resources (5P20RR016464-11) and the National Institute of General Medical Sciences (8 P20 GM103440-11).

\section{References}

Ainsworth, B. E., Haskell, W. L., Leon, A. S., Jacobs, D. R., Jr., Montoye, H. J., Sallis, J. F., \& Paffendbarger, R. S., Jr. (1993). Compendium of physical activities: Classification of energy costs of human physical activities. Medicine \& Science in Sports \& Exercise, 25, 71-80.

Alpert, P. (2010). Alternative exercise may be attractive to more individuals. Home Health Care Management \& Practice, 22, 301-304. doi:10.1177/1084822309357006

American College of Sports Medicine. (2011). Selecting and effectively using a heart rate monitor. Retrieved from http://www. 
acsm.org/docs/brochures/selecting-and-effectively-using-aheart-rate-monitor.pdf

American Heart Association. (2015). Heart and stroke statistics 2014 update: A report from the American Heart Association. Retrieved from http://circ.ahajournals.org/content/129/3/e28. full.pdf + html

Bandura, A. (1986). Social foundations of thought and action: A social cognitive theory. Englewood Cliffs, NJ: Prentice Hall.

Belza, B., Walwick, J., Shiu-Thornton, S., Schwartz, S., Taylor, M., \& LoGerfo, J. (2004). Older adult perspectives on physical activity and exercise: Voices from multiple cultures. Preventing Chronic Disease, 1(4), 1-11.

Borges, D. E., Cader, S. A., Gomes, V. D., Cruz, T. H., Carvalho, M. C., Pinto, F. M., \& Danas, E. H. (2012). The effect of ballroom dance on balance and functional autonomy among the isolated elderly. Archives of Gerontology and Geriatrics, 55, 492-496.

Butler, S., Mocarski, R., Emmons, B., \& Smallwood, R. (2014). Leaving it on the pitch: Hope solo's negotiation of conflicting gender roles on dancing with the stars. Journal of Gender Studies, 23, 362-375. doi:10.1080/09589236.2013.790798

Carraro, A., Young, M. C., \& Robazza, C. (2008). A contribution to the validation of the Physical Activity Enjoyment Scale in an Italian sample. Social Behavior and Personality, 36, 911-918.

Centers for Disease Control and Prevention. (2012). General physical activities defined by level of intensity. Retrieved from http:// www.cdc.gov/nccdphp/dnpa/physical/pdf/PA_Intensity_ table_2_1.pdf

Ceria-Ulep, C. D., Dalusung-Angosta, A., Magday-Asselstine, R. T., Castillo, M. A., Pagano, I. S., Dongmei, L., \& Wooton, A. (2013). Assessing physical activity and function in the Filipino older adults. Journal of Cultural Diversity, 20, 30-39.

Ceria-Ulep, C. D., Serafica, R., \& Tse, A. (2011). Filipino older adults' beliefs about exercise activity. Nursing Forum, 46, 240-244.

Cohen, J. (1988). Statistical power analysis for the behavioral sciences. Hillsdale, NJ: Lawrence Erlbaum.

Dalusung-Angosta, A. (2013). CHD knowledge and risk factors among Filipino-Americans connected to primary care services. Journal of the American Association of Nurse Practitioners, 25, 503-512.

Dela Cruz, F. A., \& Galang, C. B. (2008). The illness beliefs, perceptions, and practices of Filipino Americans with hypertension. Journal of the American Academy of Nurse Practitioners, 20, 118-127.

Derouich, M., \& Boutayeb, A. (2002). The effect of physical exercise on the dynamics of glucose and insulin. Journal of Biomechanics, 35, 911-917.

Fjeldsoe, B. S., Miller, Y. D., \& Marshall, A. L. (2010). MobileMums: A randomized controlled trial of an SMS-based physical activity intervention. Annals of Behavioral Medicine, 39, 101-111. doi:10.1007/s12160-010-9170-z

Ghorban, A., Ziaee, A., Yazdi, Z., Khoeyni, M. H., \& Khoshpanjeh, M. (2012). Effects of short-term exercise program on blood glucose, lipids, and hba1c in type 2 diabetes. Iranian Journal of Diabetes and Obesity, 4, 19-25.

Haskell, W. L., Lee, I. M., Pate, R. R., Powell, K. E., Blair, S. N., Franklin, B. A., . . Bauman, A. (2007). Physical activity and public health: Updated recommendation for adults from the American College of Sports Medicine and the American Heart Association. Medicine \& Science in Sports \& Exercise, 39, 1423-1434. doi:10.1249/mss.0b013e3180616b27
Health Forum. (2003). Cardiovascular risk in the Filipino community. Retrieved from http://www.nhlbi.nih.gov/health/prof/ heart/other/filipino.pdf

Hovell, M. F., Mulvihill, M. M., Buono, M. J., Liles, S., Schade, D. H., Washington, T. A., . . .Sallis, J. F. (2008). Culturally tailored aerobic exercise intervention for low-income Latinas. American Journal of Health Promotion, 22, 155-163. doi:10.4278/ajhp.22.3.155

Iso-Ahola, S. E., \& St. Clair, B. (2012). Toward a theory of exercise motivation. Quest, 52, 131-147.

Kendzierski, D., \& De Carlo, K. L. (1991). Physical Activity Enjoyment Scale: Two validation studies. Journal of Sport \& Exercise Psychology, 13, 50-64.

Lankford, D. E., Bennion, T. W., King, J., Hessing, N., Lee, L., \& Heil, D. (2014). The energy expenditure of recreational ballroom dance. International Journal of Exercise Science, 7, 228-235.

Moreno Murcia, J. A., de San Roman, M. L., Martinez Galindo, C., Alonso, N., \& Gonzalez-Cutre, D. (2008). Peers' influence on exercise enjoyment: A self-determination theory approach. Journal of Sports Science \& Medicine, 7, 23-31.

Motl, R. W., Dishman, R. K., Saunders, R., Dowda, M., Felton, G., $\&$ Pate, R. R. (2001). Measuring enjoyment of physical activity in adolescent girls. American Journal of Preventive Medicine, 21, 110-117.

Mullen, S. P., Olson, E. A., Phillips, S. M., Szabo, A. N., Wojcicki, T. R., Mailey, E. L., . . McAuley, E. (2011). Measuring enjoyment of physical activity in older adults: Invariance of the Physical Activity Enjoyment Scale (paces) across groups and time. International Journal of Behavioral Nutrition \& Physical Activity, 8, Article 103.

O’Driscoll, T., Kate Banting, L., Borkoles, E., Eime, R., \& Polman, R. (2014). A systematic literature review of sport and physical activity participation in culturally and linguistically diverse migrant populations. Journal of Immigrant Minority Health, 16, 515-530. doi:10.1007/s10903-013-9857-x

Park, S., Rink, L. D., \& Wallace, J. P. (2008). Accumulation of physical activity: Blood pressure reduction between 10-minute waking sessions. Journal of Human Hypertension, 22, 475-482.

Perez, C. A., \& Cancela Carral, J. M. (2008). Benefits of physical exercise for older adults with Alzheimer's disease. Geriatric Nursing, 29, 384-391.

Pescatello, L. S., Murphy, D., \& Costanzo, D. (2000). Low-intensity physical activity benefits blood lipids and lipoproteins in older adults living at home. Age and Ageing, 29, 433-439.

Riley, W. T., Rivera, D. E., Atienza, A. A., Nilsen, W., Allison, S. M., \& Mermelstein, R. (2011). Health behavior models in the age of mobile interventions: Are our theories up to the task? Translational Behavioral Medicine, 1, 53-71. doi:10.1007/ s13142-011-0021-7

Serafica, R. C. (2014). Dietary acculturation in Asian Americans. Journal of Cultural Diversity, 21, 145-151.

Silva Lima, M. M., \& Vieira, A. P. (2007). Ballroom dance as therapy for the elderly in Brazil. American Journal of Dance Therapy, 29, 129-142.

Song, R., June, K. J., Kim, C. G., \& Jeon, M. I. (2004). Comparisons of motivation, health behaviors, and functional status among elders in residential homes in Korea. Public Health Nursing, 21, 361-371.

Thorton, M., Marshall, S., McComas, J., Finestone, H., McCormick, A., \& Sveistrup, H. (2005). Benefits of activity and virtual 
reality based balance exercise programmes for adults with traumatic brain injury: Perceptions of participants and their caregivers. Brain Injury, 19, 989-1000.

U.S. Census Bureau. (2010). Census shows Asians are fastestgrowing race group. Retrieved from http://www.census. gov/newsroom/releases/archives/2010_census/cb12-cn22. html

U.S. Department of Health and Human Services. (2008). Physical activity guidelines for Americans. Retrieved from http://www. health.gov/PAGuidelines/pdf/paguide.pdf

Ursua, R. A., Islam, N. S., Aguilar, D. E., Wyatt, L. C., Tandon, S. D., Abesamis-Mendoza, N., . . Trinh-Shevrin, C. (2013). Predictors of hypertension among Filipino immigrants in the Northeast US. Journal of Community Health, 38, 847-855. doi:10.1007/s10900-013-9689-6

Vahabi, M., Beanlands, H., Sidani, S., \& Fredericks, S. (2012). South Asian women's beliefs about physical activity and dancing as a form of exercise. Journal of Immigrant \& Refugee Studies, 12, 139-161.

Zou, Y., Zhang, M., \& Maddock, J. E. (2012). Assessing physical activity and related correlates among adults in Hawai'i. Hawai'i Journal of Medicine \& Public Health, 71, 310-318.

\section{Author Biographies}

Alona D. Angosta, PhD, MSN, APRN, NP-C completed her PhD at the University of Hawaii at Manoa. She currently teaches in the baccalaureate and graduate nursing programs at the University of Nevada, Las Vegas. Her research interest include lifestyle interventions with emphasis on self-management and physical activity in decreasing obesity and cardiovascular disease risk; chronic illness among vulnerabe populations; and reducing health disparities.

Reimund Serafica, PhD, MSN, RN, is an assistant professor at the University of Nevada, Las Vegas and teaches in the baccalaureate and graduate nursing programs. His research interest include dietary acculturation, dietary self-management, and chronic illness interventions among first and second generation immigrants in the United States.

Sheniz Moonie, $\mathrm{PhD}$, MS, is an associate professor of Epidemiology and Biostatistics in the School of Community Health Sciences at University of Nevada, Las Vegas. She serves as the Epidemiology and Biostatistics Program and the MPH Program coordinator. Her research focus is pediatric asthma and she has an active research study with the University of Nevada School Of Medicine investigating the relationship between asthma and obesity among children. 